\title{
Kinetic characterization of the soluble butane monooxygenase from Thauera butanivorans, formerly 'Pseudomonas butanovora'
}

\author{
Correspondence \\ Daniel J. Arp \\ arpd@science.oregonstate.edu
}

\author{
Richard B. Cooley, ${ }^{1}$ Bradley L. Dubbels, ${ }^{2}$ Luis A. Sayavedra-Soto, ${ }^{2}$ \\ Peter J. Bottomley ${ }^{3}$ and Daniel J. Arp ${ }^{2}$ \\ 1Department of Biochemistry and Biophysics, Oregon State University, Corvallis, OR 97331, USA \\ ${ }^{2}$ Department of Botany and Plant Pathology, Oregon State University, Corvallis, OR 97331, USA \\ ${ }^{3}$ Department of Microbiology, Oregon State University, Corvallis, OR 97331, USA
}

Received 9 February 2009

Revised 19 March 2009

Accepted 24 March 2009
Soluble butane monooxygenase (sBMO), a three-component di-iron monooxygenase complex expressed by the $\mathrm{C}_{2}-\mathrm{C}_{9}$ alkane-utilizing bacterium Thauera butanivorans, was kinetically characterized by measuring substrate specificities for $\mathrm{C}_{1}-\mathrm{C}_{5}$ alkanes and product inhibition profiles. sBMO has high sequence homology with soluble methane monooxygenase (sMMO) and shares a similar substrate range, including gaseous and liquid alkanes, aromatics, alkenes and halogenated xenobiotics. Results indicated that butane was the preferred substrate (defined by $k_{\text {cat }}: K_{\mathrm{m}}$ ratios). Relative rates of oxidation for $\mathrm{C}_{1}-\mathrm{C}_{5}$ alkanes differed minimally, implying that substrate specificity is heavily influenced by differences in substrate $K_{\mathrm{m}}$ values. The low micromolar $K_{\mathrm{m}}$ for linear $\mathrm{C}_{2}-\mathrm{C}_{5}$ alkanes and the millimolar $K_{\mathrm{m}}$ for methane demonstrate that sBMO is two to three orders of magnitude more specific for physiologically relevant substrates of $T$. butanivorans. Methanol, the product of methane oxidation and also a substrate itself, was found to have similar $K_{\mathrm{m}}$ and $k_{\mathrm{cat}}$ values to those of methane. This inability to kinetically discriminate between the $C_{1}$ alkane and $C_{1}$ alcohol is observed as a steady-state concentration of methanol during the two-step oxidation of methane to formaldehyde by sBMO. Unlike methanol, alcohols with chain length $\mathrm{C}_{2}-\mathrm{C}_{5}$ do not compete effectively with their respective alkane substrates. Results from product inhibition experiments suggest that the geometry of the active site is optimized for linear molecules four to five carbons in length and is influenced by the regulatory protein component $\mathrm{B}$ (butane monooxygenase regulatory component; $\mathrm{BMOB}$ ). The data suggest that alkane oxidation by sBMO is highly specialized for the turnover of $\mathrm{C}_{3}-\mathrm{C}_{5}$ alkanes and the release of their respective alcohol products. Additionally, sBMO is particularly efficient at preventing methane oxidation during growth on linear alkanes $\geqslant \mathrm{C}_{2}$, despite its high sequence homology with sMMO. These results represent, to the best of our knowledge, the first kinetic in vitro characterization of the closest known homologue of sMMO.

\section{INTRODUCTION}

Aliphatic alkanes are used as a sole source of carbon and energy by a diverse range of aerobic prokaryotes (Shennan, 2006). To initiate growth on $\mathrm{C}_{2}-\mathrm{C}_{9}$ alkanes, the Gramnegative $\beta$-proteobacterium Thauera butanivorans, formerly called 'Pseudomonas butanovora' (Dubbels et al., 2009), expresses a carboxylate-bridged non-haem di-iron monooxygenase, commonly referred to as soluble butane

Abbreviations: $\mathrm{BMOB}$, butane monooxygenase regulatory component; $\mathrm{BMOH}$, butane monooxygenase hydroxylase; $\mathrm{BMOR}$, butane monooxygenase reductase; $\mathrm{MMOB}$, methane monooxygenase regulatory component; $\mathrm{MMOH}$, methane monooxygenase hydroxylase; sBMO, soluble butane monooxygenase; sMMO, soluble methane monooxygenase; WT, wild-type. monooxygenase (sBMO) (Sluis et al., 2002; Takahashi et al., 1980). sBMO belongs to a family of bacterial multicomponent monooxygenases which includes soluble methane monooxygenases (sMMOs), phenol hydroxylases (PHs) and aromatic/alkene monooxygenases (TMOs) (Leahy et al., 2003; Sluis et al., 2002). Due to their unusually large substrate ranges, these powerful oxidizers are of particular interest for their potential in bioremediation (Enzien et al., 1994; Halsey et al., 2007; Parales et al., 2002; Smith \& Dalton, 2004) and their ability to serve as industrial biocatalysts (Burton, 2003; Parales et al., 2002).

The expression of sBMO is induced by the presence of 1butanol and butyraldehyde, and is repressed by lactate and succinate (Sayavedra-Soto et al., 2005). When T. butani- 
vorans is grown on butane, sBMO oxidizes butane primarily to 1-butanol ( $>85 \%$ terminal oxidation), which is then further oxidized to butyrate via butyraldehyde (Arp, 1999). Further metabolism of butyrate probably proceeds through butyryl-CoA prior to $\beta$-oxidation (Arp, 1999). The metabolic pathway of odd-chain or subterminally oxidized alkanes has not yet been fully characterized in $T$. butanivorans; however, it is known that the metabolism of odd- and even-chain alkane growth substrates is differentially controlled (Doughty et al., 2007). Although sBMO is capable of oxidizing methane to methanol (Halsey et al., 2006), T. butanivorans cannot assimilate $C_{1}$ compounds into biomass.

sBMO is a three-component complex that was recently purified and found to have a similar architecture to that of sMMO: (i) a $250 \mathrm{kDa}$ hydroxylase component (butane monooxygenase hydroxylase; BMOH) with $(\alpha \beta \gamma)_{2}$ subunit composition that, by analogy with sMMO, contains the diiron active site in the $\alpha$-subunit; (ii) a $40 \mathrm{kDa}$ flavo-ironsulfur-containing reductase (butane monooxygenase reductase; $\mathrm{BMOR}$ ) that shuttles electrons from NADH to the active site of $\mathrm{BMOH}$; and (iii) a $15 \mathrm{kDa}$ regulatory protein (butane monooxygenase regulatory component; $\mathrm{BMOB}$ ) that enhances the overall activity of the complex (Dubbels et al., 2007). Sequence analysis shows BMOH to be most closely related to $\operatorname{sMMO}(65,42$ and $38 \%$ amino acid identity in the $\alpha$-, $\beta$ - and $\gamma$-subunits of $\mathrm{BMOH}$, respectively) (Sluis et al., 2002). Additionally, sequence alignment and structural modelling show that all residues directly lining the active site cavity of $\mathrm{BMOH}$ are the same as those in the methane monooxygenase hydroxylase $(\mathrm{MMOH})$. Despite the similarities, several biochemical observations indicate that sBMO represents a class distinct from the sMMO family: (i) methanol accumulation ceases during methane oxidation once $\sim 20-50 \mu \mathrm{M}$ has been reached (Halsey et al., 2006), whereas sMMO can continue to accumulate methanol; (ii) sBMO is predominantly a terminal hydroxylator of intermediate-chain-length alkanes (Dubbels et al., 2007), whereas sMMO forms secondary alcohols (Froland et al., 1992); (iii) product regioselectivity is minimally altered by the presence of BMOB (Dubbels et al., 2007), unlike sMMO (Froland et al., 1992); (iv) catalase is required to maintain hydroxylase activity during steady-state turnover (Dubbels et al., 2007) but not to maintain sMMO activity; and (v) the use of peroxide in the 'peroxide shunt' mechanism of substrate oxidation is three orders of magnitude less efficient in sBMO than in sMMO (Dubbels et al., 2007).

The structural basis of the catalytic properties of these alkane monooxygenases is still poorly understood, most notably due to a lack of enzyme isolation and subsequent in vitro characterization (van Beilen \& Funhoff, 2007). Even though crystal structures of apo-MMOH and productbound $\mathrm{MMOH}$ have been reported (Rosenzweig et al., 1997; Sazinsky \& Lippard, 2005), the fully buried active site does not appear to be accessible or large enough to accommodate known substrates such as naphthalene or biphenyl. A few mutational studies of $\mathrm{BMOH}$ and $\mathrm{MMOH}$ have provided insight into this field, however. Substitution of residue Gly113 in the $\alpha$-subunit of BMOH with the equivalent residue of $\mathrm{MMOH} \alpha$ (Asn) results in a shift of properties to those more characteristic of sMMO, such as increased methanol accumulation and an alteration in product regioselectivity from primary to secondary hydroxylation (Halsey et al., 2006). Alterations in the 'leucine gate' residue of $\mathrm{MMOH} \alpha$ (Leu110) have shown that it is critical in defining the regioselectivity of sMMO (Borodina et al., 2007).

Given the wide substrate range of alkane monooxygenases, a comprehensive kinetic characterization of sBMO would help provide insights into the mechanism of substrate specificity. Here, we report a characterization of the substrate specificity for $\mathrm{sBMO}$ and show that, despite having the same active site residues as sMMO, sBMO is poorly suited for methane yet highly optimized for linear molecules four to five carbons in length. Since measurable substrate turnover is possible without $\mathrm{BMOB}$, we were also able to directly observe a function for BMOB in catalysis using product inhibitors. Such types of experiments have not been possible with sMMO because substrate turnover is too slow without the methane monooxygenase regulatory component (MMOB).

\section{METHODS}

Chemicals. Gaseous alkanes were of reagent grade. Methane was purchased from Airco. Ethane was purchased from Matheson. Propane and butane were purchased from Airgas. Pentane was purchased as reagent grade from VWR. NADH was purchased from Research Organics and residual ethanol was removed by repeated lyophilization in $25 \mathrm{mM}$ PIPES, pH 7.2. Bovine liver catalase was purchased from Sigma. All other chemicals were obtained from Aldrich.

Bacterial cultivation and BMOH/BMOR purification. Wild-type (WT) T. butanivorans was grown on butane as described previously (Dubbels et al., 2007) with the exception that $100 \mu \mathrm{M} \mathrm{Fe}{ }^{3+}$-EDTA was used as an iron source instead of $500 \mu \mathrm{M} \mathrm{FeSO}_{4} \cdot 7 \mathrm{H}_{2} \mathrm{O}$. Mutant strain G113N, which has residue 113 of the $\alpha$-subunit of $\mathrm{BMOH}$ altered from Gly to Asn (Halsey et al., 2006), was grown identically to WT except that $50 \mu \mathrm{M} \mathrm{MnCl} 2$ and $10 \mu \mathrm{M} \mathrm{Na} \mathrm{NaO}_{3}$ were added to the medium to facilitate the downstream metabolism of secondary alcohols. WT BMOH and BMOR components of sBMO were purified as previously described (Dubbels et al., 2007). The G113N BMOH was purified identically to the WT hydroxylase. The alternative iron source yielded $\mathrm{BMOH}$ that exhibited much tighter elution profiles off the Sephacryl S-300 HR gel-filtration column due to significantly reduced self-aggregation, as determined by dynamic light scattering. Additionally, the iron content of $\mathrm{BMOH}$, as measured by the ferrozine spectrophotometric assay (Percival, 1991), contained 2.1-2.4 irons per active site rather than the 1.4-1.8 reported previously (Dubbels et al., 2007). Typical preparations of the enzyme complex resulted in activities ranging

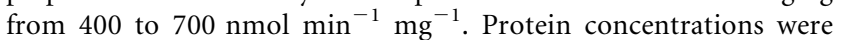
determined by optical absorption at $280 \mathrm{~nm}$ using absorption coefficients of 2.2 and $0.56 \mathrm{ml} \mathrm{mg}^{-1} \mathrm{~cm}^{-1}$ for BMOH and BMOR, respectively. 
Development of a recombinant BMOB expression system. Purification of $\mathrm{BMOH}$ and $\mathrm{BMOR}$ from the native host yielded large quantities of highly active protein, and so no recombinant expression system was needed. However, purification of BMOB from the native host required several additional purification steps and the yields were not always satisfactory. We therefore chose to develop a recombinant expression system for BMOB that provided a simpler purification process with significantly increased yields.

To create the recombinant $\mathrm{BMOB}$ expression system, genomic and plasmid DNA were first isolated according to established protocols (Ausubel et al., 2003). Primers for the amplification of BMOB were as follows: bmobfNdeI, 5'-CAGGGGCAGACCATATGTCAAACGT-3', and bmobrBamHI, 5'-CGCACCGGTGTGTGGATCCAAACCT-3'. Bases indicated in bold type are the restriction sites included for subsequent cloning into the expression vector. A standard PCR was carried out with the above primers with Taq (Promega). The PCR product was gel-purified with QIAEX II (Qiagen) and restricted with $N d e \mathrm{I}$ and $\mathrm{BamHI}$ (Promega). Gel purification of the restriction digest was performed as described above, and the isolated PCR product was ligated into NdeI- and BamHI-digested pT7-7 (Tabor \& Richardson, 1985). The ligation reaction was transformed into chemically competent Escherichia coli JM109 (Sambrook et al., 1989). Plasmid DNA was isolated and the sequence of $b m o b$ was confirmed by DNA sequencing at the Center for Genome Research and Biocomputing at Oregon State University. The resulting plasmid, pBD400, was transformed into chemically competent E. coli BL21(DE3) (Novagen) for subsequent expression and purification.

Expression and purification of recombinant BMOB. E. coli BL21(DE3) cells containing the pBD400 plasmid were grown in $31 \mathrm{LB}$ medium in the presence of $100 \mu \mathrm{g}$ ampicillin $\mathrm{ml}^{-1}$ at $37{ }^{\circ} \mathrm{C}$ to $\mathrm{OD}_{600}$ 0.8 . Protein expression was stimulated by the addition of $1 \mathrm{mM}$ IPTG. After $3 \mathrm{~h}$ further growth, cells were centrifuged at $5000 \mathrm{~g}$ for $20 \mathrm{~min}$ and stored at $-70{ }^{\circ} \mathrm{C}$. Typically, yields of $4-5 \mathrm{~g}$ cell paste $1^{-1}$ were obtained.

All purification steps of recombinant BMOB (rBMOB) were performed at $4{ }^{\circ} \mathrm{C}$. Frozen E. coli BL21(DE3) cell paste $(15 \mathrm{~g})$ was resuspended in $25 \mathrm{mM}$ PIPES, $\mathrm{pH} 7.2$, to a total volume of $40 \mathrm{ml}$ containing $1000 \mathrm{U}$ DNase I (Sigma). Cells were lysed by two passes through a French pressure cell disrupter at $52000 \mathrm{~Pa}$, and then centrifuged at $10000 \mathrm{~g}$ for $20 \mathrm{~min}$. The supernatant was carefully decanted, diluted to $60 \mathrm{ml}$ and centrifuged at $150000 \mathrm{~g}$ for $2 \mathrm{~h}$. The resulting cell-free lysate was decanted, adjusted to $\mathrm{pH} 7.2$, and loaded onto a DEAE-Sepharose FF column $(90 \mathrm{~mm} \times 30 \mathrm{~mm})$ pre-equilibrated with $25 \mathrm{mM}$ PIPES, pH 7.2, at $2 \mathrm{ml} \mathrm{min}^{-1}$. The column was washed with five column volumes of the same buffer at a linear flow rate of $2 \mathrm{ml} \mathrm{min}^{-1}$, after which a $0-0.4 \mathrm{M} \mathrm{KCl}$ linear gradient was applied over four column volumes. Fractions containing rBMOB eluted between 0.2 and $0.3 \mathrm{M} \mathrm{KCl}$. These fractions were pooled, repeatedly dialysed against $25 \mathrm{mM}$ PIPES, pH 7.2, with $150 \mathrm{mM} \mathrm{KCl}$, and concentrated to $3 \mathrm{ml}$ total volume via ultrafiltration. The concentrate was then applied to Sephadex 75 FF gel-filtration columns $(550 \mathrm{~mm} \times 25 \mathrm{~mm})$ pre-equilibrated with the same buffer at a linear flow rate of $0.5 \mathrm{ml} \mathrm{min}{ }^{-1}$. Fractions containing purified rBMOB were pooled, dialysed against $25 \mathrm{mM}$ PIPES, $\mathrm{pH} 7.2$, concentrated to $2 \mathrm{mM}$, flash-frozen in liquid nitrogen and stored at $-70{ }^{\circ} \mathrm{C}$. From $15 \mathrm{~g}$ of cells, $200-250 \mathrm{mg}$ purified $\mathrm{rBMOB}$ was obtained. $\mathrm{rBMOB}$ was found to display the same enhancement of sBMO activity as native $\mathrm{BMOB}$, alter the product distribution similarly, have the same mobility on SDS-PAGE, and have identical molecular mass as determined by MALDI-TOF MS. rBMOB also displayed the same partial dimerization through intermolecular disulfide linkage as native BMOB (Dubbels et al., 2007). Accordingly, all reactions in this study were performed with the recombinant form of $\mathrm{BMOB}$. Concentrations were determined by
$A_{280}$ measurement using an absorption coefficient of $1.2 \mathrm{ml} \mathrm{mg}^{-1}$ $\mathrm{cm}^{-1}$.

Determination of methane $\boldsymbol{K}_{\mathbf{m}}$. Vials $(7.7 \mathrm{ml})$ containing a stir bar and a $0.5 \mathrm{ml}$ aliquot of $0.1 \mu \mathrm{M} \mathrm{BMOH}, 0.3 \mu \mathrm{M}$ BMOB, $0.6 \mu \mathrm{M}$ BMOR and $2400 \mathrm{U}$ catalase $\mathrm{ml}^{-1}$ in $25 \mathrm{mM}$ PIPES, pH 7.2, were crimp-sealed with butyl rubber septa. Methane was added directly as an overpressure. For higher concentrations, however, methane was used to refill the head space, to which additional methane and $20 \%$ $(\mathrm{v} / \mathrm{v})$ oxygen were added as an overpressure. This mixture was allowed to equilibrate at $25{ }^{\circ} \mathrm{C}$ for $5 \mathrm{~min}$ with gentle stirring. To initiate the reaction, $\mathrm{NADH}$ was added via a gas-tight syringe to a final concentration of $1 \mathrm{mM}$. Samples $(2 \mu \mathrm{l})$ were removed and injected into a Shimadzu GC-8A gas chromatograph equipped with a flame-ionization detector and a stainless steel column packed with Porapak Q (Alltech) (80/100 mesh). Although methanol accumulation halts after the production of $\sim 30 \mu \mathrm{M}$ methanol (Halsey et al., 2006), linear rates could be obtained for the first 5-10 min prior to slowing of the reaction. Methane concentrations were based on calculations using a Henry's constant of $0.0014 \mathrm{M}$ atm $^{-1}$ at $25{ }^{\circ} \mathrm{C}$ (Lide \& Frederikse, 1995). The $K_{\mathrm{m}}$ of methane was determined by fitting the initial rates of reactions as a function of substrate concentration using Origin Pro 7.5 (OriginLab) according to the following equation:

$v_{0}=\frac{V \times[\text { Methane }]}{K_{\mathrm{m}}+[\text { Methane }]}$

(Equation 1)

where $v_{0}$ is the initial rate of reaction, $V$ is the maximal rate of methanol accumulation under saturating concentrations of substrate, [Methane] is the aqueous concentration of methane and $K_{\mathrm{m}}$ is the Michaelis constant. Methanol concentrations were determined based on a standard curve produced from authentic methanol in the same buffered conditions. All reported errors are SDs from three independent replicates.

Determination of the $\boldsymbol{K}_{\mathrm{m}}$ for $\mathbf{C}_{\mathbf{2}}-\mathbf{C}_{\mathbf{5}}$ alkanes. $K_{\mathrm{m}}$ measurements for longer-chain alkanes could not be performed due to slow diffusion rates and limited detection by GC at submicromolar concentrations of product. Instead, the $K_{\mathrm{m}}$ values for alkanes were measured indirectly by competition with nitrobenzene. In a sealed quartz cuvette, $0.5 \mathrm{ml}$ of a mixture containing $0.06 \mu \mathrm{M} \mathrm{BMOH}, 0.18 \mu \mathrm{M}$ BMOB, $0.36 \mu \mathrm{M}$ BMOR, $2400 \mathrm{U}$ catalase $\mathrm{ml}^{-1}$ and $1 \mathrm{mM}$ nitrobenzene in $25 \mathrm{mM}$ PIPES, pH 7.2, was incubated for 5 min with varying amounts of gaseous alkane added to the head space. Reactions were initiated by the addition of $1 \mathrm{mM} \mathrm{NADH}$, and monitored by the formation of $p$-nitrophenol $\left(\varepsilon_{404 \mathrm{~nm}}=15 \mathrm{mM}^{-1} \mathrm{~cm}^{-1}\right)$ at $404 \mathrm{~nm}$ in a Beckman DU-640 spectrophotometer. The initial linear portion of the reaction curve $(\sim 1-2 \mathrm{~min})$ was taken as the initial reaction rate of nitrobenzene formation when in competition with the alkane. The $K_{\mathrm{m}}$ of the alkane was determined by fitting the following equation:

$v_{0}=\frac{V \times[\mathrm{S}]}{K_{\mathrm{m} 2}\left(1+[\mathrm{a}] / K_{\mathrm{m}}\right)+[\mathrm{S}]}$

(Equation 2)

where $v_{0}$ is the initial rate of nitrobenzene formation, $V$ is the maximal reaction rate, $[S]$ is the initial concentration of nitrobenzene, $K_{\mathrm{m} 2}$ is the Michaelis constant for nitrobenzene $(40 \mu \mathrm{M})$, [a] is the aqueous concentration of the alkane, and $K_{\mathrm{m}}$ is the Michaelis constant for the alkane. Aqueous concentrations of ethane, propane, butane and pentane were determined using Henry's constants of 0.0019 , $0.0014,0.0011$ and $0.0008 \mathrm{M} \mathrm{atm}^{-1}$, respectively. To ensure the accuracy of this method, a similar analysis of methane competition with nitrobenzene was performed in an identical manner to that of ethane, propane, butane and pentane, except that only $50 \mu \mathrm{M}$ nitrobenzene was used instead of $1 \mathrm{mM}$. 
Determination of alcohol inhibition constants. A sealed quartz cuvette containing $0.25 \mu \mathrm{M} \mathrm{BMOH}, 0.75 \mu \mathrm{M}$ BMOB, $1.5 \mu \mathrm{M}$ BMOR, $2400 \mathrm{U}$ catalase $\mathrm{ml}^{-1}$ and $1 \mathrm{mM}$ nitrobenzene in $25 \mathrm{mM}$ PIPES, pH 7.2, was incubated with varying amounts of primary and secondary alcohols for $5 \mathrm{~min}$ prior to reaction initiation with $1 \mathrm{mM}$ NADH. Three titrations per alcohol were performed, each with different concentrations of nitrobenzene (50, 100 or $200 \mu \mathrm{M})$ in order to determine the type of inhibition. Linear rates of $p$-nitrophenol formation were monitored by the increase in $A_{404}$ for $2 \mathrm{~min}$. For experiments without BMOB, reactions were monitored for $5 \mathrm{~min}$ due to slower rates of product formation. Competitive and uncompetitive inhibition constants were modelled using the mixed inhibitory equation (CornishBowden, 1995):

$v_{0}=\frac{V \times[\mathrm{S}]}{K_{\mathrm{m}}\left(1+[\mathrm{i}] / K_{\mathrm{ic}}\right)+[\mathrm{S}]\left(1+[\mathrm{i}] / K_{\mathrm{iu}}\right)}$

(Equation 3)

where [i] is the concentration of inhibitor and $K_{\mathrm{ic}}$ and $K_{\mathrm{iu}}$ are the competitive and uncompetitive inhibition constants, respectively. All observed inhibition data were fitted to Equation 3 with $R^{2}>0.97$. Stock nitrobenzene concentrations were determined using a molar absorption coefficient of $7800 \mathrm{M}^{-1} \mathrm{~cm}^{-1}$ at $268 \mathrm{~nm}$ (Zhu et al., 2007).

Formaldehyde analysis. Quantification of formaldehyde was performed by derivatization with acetoacetanilide and subsequent fluorescence detection, as described elsewhere (Li et al., 2007). Concentrations of formaldehyde were based on a standard curve made from a stock solution of known concentration. Formaldehyde stock concentrations were determined by titration of a diluted sample with a molar excess of iodine $\left(\mathrm{I}_{2}\right)$ in the presence of $0.2 \mathrm{M}$ $\mathrm{NaOH}$. After $15 \mathrm{~min}$, the excess $\mathrm{I}_{2}$ was acidified with $\mathrm{H}_{2} \mathrm{SO}_{4}$ and back-titrated with $0.1 \mathrm{M}$ sodium thiosulfate in the presence of $0.02 \%(\mathrm{w} / \mathrm{v})$ starch indicator. The same procedure was repeated without formaldehyde. The difference in thiosulfate needed to titrate the two solutions was used to determine the original concentration of formaldehyde.

\section{RESULTS}

\section{Oxidation of alkanes by sBMO}

In order to further understand the substrate specificity of sBMO, kinetic parameters $K_{\mathrm{m}}$ and $k_{\text {cat }}$ were determined for linear $\mathrm{C}_{1}-\mathrm{C}_{5}$ alkanes. Although methane is known to be a substrate of sBMO, the accumulation of its product, methanol, has previously been shown to cease once methanol concentrations reach $\sim 20-30 \mu \mathrm{M}$ (Halsey et al., 2006). However, at concentrations ranging from 0 to $15 \mu \mathrm{M}$, the rates of methanol formation were both constant and dependent on the concentration of aqueous methane. These rates became saturated above $5 \mathrm{mM}$ methane, allowing for a direct measurement of the $K_{\mathrm{m}}$ for methane (Fig. 1a). Doubling the enzyme concentration along the first-order region of the titration curve resulted in a doubling of the reaction rate, indicating that the reactions were not diffusion-limited. In contrast to the low micromolar $K_{\mathrm{m}}$ of sMMO for methane $(3-13 \mu \mathrm{M}$ ) (Green \& Dalton, 1986; Nesheim \& Lipscomb, 1996), the $K_{\mathrm{m}}$ of sBMO for methane was $1.10 \pm 0.14 \mathrm{mM}$ (Table 1). Determination of $K_{\mathrm{m}}$ values for the $\mathrm{C}_{2}-\mathrm{C}_{5}$ growth substrates could not be performed by direct measurement due to limited diffusion rates at low concentrations. Instead, $K_{\mathrm{m}}$ values were derived by competition experiments between nitrobenzene and the alkane substrates according to Equation 2 (Fig. 1b). The $K_{\mathrm{m}}$ for methane was also measured in this manner, giving similar results to the direct measurement $(1.25 \pm 0.12 \mathrm{mM}$, data not shown).

The $K_{\mathrm{m}}$ values listed in Table 1 indicate a sharp transition of large magnitude from methane to ethane, but less of a difference between propane, butane and pentane. Although
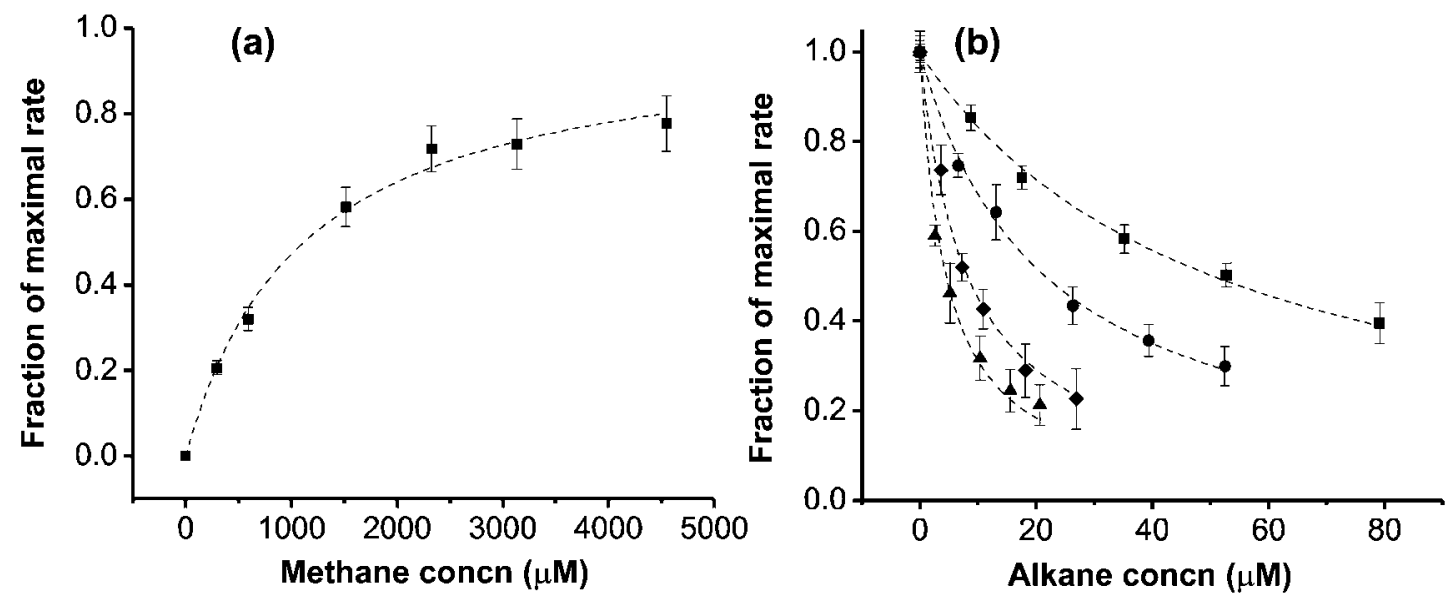

Fig. 1. Determination of $K_{\mathrm{m}}$ values for $\mathrm{C}_{1}-\mathrm{C}_{5}$ alkanes. (a) Dependence of the rate of methanol formation on the aqueous concentration of methane. The dashed line is the best fit line according to Equation 1. A fractional rate of 1.0 is equal to

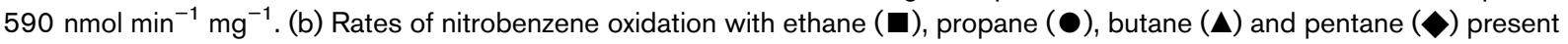
as a competing substrate. Best fit lines are modelled from the data according to Equation 2. Error bars represent SD from three replicates. A fractional rate of 1.0 is equal to $450 \mathrm{nmol} \mathrm{min}^{-1} \mathrm{mg}^{-1}$. 
Table 1. Kinetic parameters for $\mathrm{C}_{1}-\mathrm{C}_{5}$ substrates with WT sBMO

ND, Not detected. Error values represent SD from three replicates.

\begin{tabular}{|c|c|c|c|c|c|c|c|}
\hline \multirow[t]{2}{*}{ Substrate } & \multirow[t]{2}{*}{$K_{\mathrm{m}}(\mu \mathrm{M})$} & \multicolumn{4}{|c|}{$k_{\text {cat }}\left(\mathrm{s}^{-1}\right)^{\star}$} & \multirow[t]{2}{*}{$k_{\text {cat }} / K_{\mathrm{m}}\left(\mu \mathrm{M}^{-1} \mathrm{~s}^{-1}\right)$} & \multirow{2}{*}{$\begin{array}{c}\text { Measured } \\
\text { specificity } \dagger\end{array}$} \\
\hline & & Total & $1-\mathrm{OH}$ & 2-OH & 3-OH & & \\
\hline Methane & $1100 \pm 140 \ddagger$ & $1.3 \pm 0.1 \S$ & - & - & - & $0.0012 \pm 0.0002$ & ND \\
\hline Ethane & $2.2 \pm 0.111$ & $0.76 \pm 0.05 \neq$ & $0.76 \pm 0.05$ & - & - & $0.35 \pm 0.03$ & $1 \pm 0.06$ \\
\hline Propane & $0.94 \pm 0.05 \mathrm{II}$ & $0.65 \pm 0.06 \neq$ & $0.55 \pm 0.05$ & $0.098 \pm 0.01$ & - & $0.69 \pm 0.07$ & $2.4 \pm 0.2$ \\
\hline Butane & $0.24 \pm 0.02 \mathrm{II}$ & $0.60 \pm 0.03 \ddagger$ & $0.48 \pm 0.02$ & $0.12 \pm 0.01$ & - & $2.5 \pm 0.2$ & $5.7 \pm 0.2$ \\
\hline Pentane & $0.34 \pm 0.03 \mathrm{II}$ & $0.39 \pm 0.03 \ddagger$ & $0.34 \pm 0.02$ & $0.039 \pm 0.01$ & $0.008 \pm 0.001$ & $1.2 \pm 0.1$ & $4.4 \pm 0.1$ \\
\hline
\end{tabular}

${ }^{*}$ The 1-OH column represents the rate of hydroxylation on the primary carbon, 2-OH for the secondary carbon at position 2, 3-OH for the secondary carbon at position 3 , and Total represents the sum of all products.

$\dagger$ Direct measurement by competition using an equal concentration of all alkanes in a single reaction, relative to ethane.

$\ddagger$ Direct measurement.

§Extrapolated from Michaelis plot.

IICalculated from competition with nitrobenzene.

preferential binding of substrates is likely to be heavily influenced by the 'hydrophobic effect', this cannot explain the drop of nearly three orders of magnitude in $K_{\mathrm{m}}$ from methane to ethane (if $K_{\mathrm{m}}$ constants are assumed to correlate with binding affinity). Alternatively, given the Bi Uni Uni Bi Ping Pong kinetic mechanism proposed for sMMO (Green \& Dalton, 1986), the observed $K_{\mathrm{m}}$ for the alkane should be heavily influenced by the rate of alcohol release (Leskovac, 2003). As alcohol release becomes rate limiting, which has been reported for sMMO (Lee et al., 1993; Wallar \& Lipscomb, 2001), the $K_{\mathrm{m}}$ of the substrate drops below the $K_{\mathrm{d}}$. Such a scenario would explain the large drop in the $K_{\mathrm{m}}$ for ethane. Similar arguments have been proposed for protein kinase A (Werner et al., 1996). The observed maximal turnover rates for methane and ethane listed in Table 1 also support this hypothesis. If the rate-limiting step of the reaction was turnover, the cleavage of a $\mathrm{C}-\mathrm{H}$ bond for ethane should be three orders of magnitude faster, since its dissociation energy is about $4 \mathrm{kcal} \mathrm{mol}^{-1}\left(16.7 \mathrm{~kJ} \mathrm{~mol}^{-1}\right)$ weaker than that of methane (Korth \& Sicking, 1997; Zheng \& Lipscomb, 2006). Such a dramatic increase in ethane turnover was not observed in sBMO, nor in earlier studies with sMMO (Green \& Dalton, 1986).

Total turnover rates for $\mathrm{C}_{1}-\mathrm{C}_{5}$ substrates were also determined (Table 1). The individual rates of the different alcohol isomers from the oxidation of $\mathrm{C}_{3}-\mathrm{C}_{5}$ alkanes were also proportional to previously reported product distributions (Dubbels et al., 2007). The ratio $k_{\text {cat }}: K_{\mathrm{m}}$ indicated sBMO to be most specific for butane; however, propane and pentane were not substantially different. sBMO was nearly 280 -fold more specific for ethane than methane. To confirm the calculated substrate specificities, competition experiments were performed with a mixture of equal concentrations of $\mathrm{C}_{1}-\mathrm{C}_{5}$ alkanes. Although methanol formation was not detected, the relative amounts of each
$\mathrm{C}_{2}-\mathrm{C}_{5}$ alcohol produced were similar to those predicted by the measured $k_{\text {cat }}: K_{\mathrm{m}}$ ratio (Table 1 ), providing further evidence that the sBMO enzyme is optimized for butane as a substrate while minimizing $\mathrm{C}_{1}$ oxidation.

\section{Product inhibition of sBMO}

Halogenated alcohols have been shown by X-ray crystallography to bind directly in the active site of sMMO, with the oxygen atom of the alcohol group bridging the di-iron centre (Sazinsky \& Lippard, 2005). The binding of primary and secondary alcohols to sBMO was characterized in order to gain additional insight into the approximate geometry of the active site. Methanol inhibition of nitrobenzene oxidation was modelled with a mixed inhibitory scenario (Equation 3), which indicated that the inhibition was purely competitive and relatively weak $\left(K_{\mathrm{ic}}=1.25 \pm 0.06 \mathrm{mM}\right)$. Previously, our group hypothesized that the plateau of methanol accumulation at $\sim 30 \mu \mathrm{M}$ during methane oxidation was the result of strong product inhibition (Halsey et al., 2006). However, the millimolar $K_{\mathrm{ic}}$ observed for methanol and similar $K_{\mathrm{m}}$ for methane do not support the conclusion that methanol would effectively inhibit methane oxidation at such low concentrations. More insights into the special case of methane oxidation are discussed later in this section.

Primary alcohols $\mathrm{C}_{1}-\mathrm{C}_{6}$ displayed pure competitive inhibition with nitrobenzene. An average increase of $0.69 \pm 0.1 \mathrm{kcal} \mathrm{mol}^{-1}\left(2.9 \mathrm{~kJ} \mathrm{~mol}^{-1}\right)$ per methylene group was observed for primary $\mathrm{C}_{1}-\mathrm{C}_{5}$ alcohols (Fig. 2, shaded bars). Mutational analyses of hydrophobic residues in the interior of proteins have suggested that each methylene group contributes approximately $1.1 \pm 0.5 \mathrm{kcal}$ (4.6 \pm $2.1 \mathrm{~kJ}$ ) of stability per mole per methylene group (Pace et al., 1996). It would appear, therefore, that the binding of $\mathrm{C}_{1}-\mathrm{C}_{5}$ alcohols to the fully buried, hydrophobic active site 


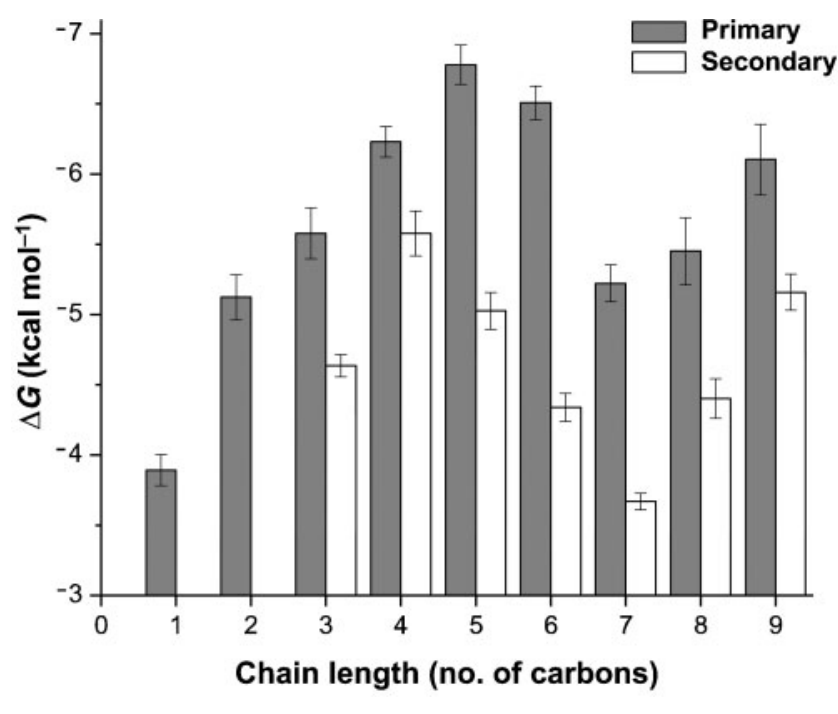

Fig. 2. Alcohol binding energies to $\mathrm{BMOH}$. Binding energies of primary alcohols (shaded bars) and secondary alcohols with the hydroxyl group at the second carbon position (white bars) were calculated from the observed competitive inhibition constants using the equation $\Delta G=-\mathrm{R} T \ln \left(K_{\mathrm{ic}}{ }^{-1}\right)$, where $T$ is the temperature in Kelvin $(298 \mathrm{~K})$ and $\mathrm{R}$ is the universal gas constant.

of $\mathrm{BMOH}$ is heavily influenced by this 'hydrophobic effect'. After $\mathrm{C}_{5}$, however, binding affinity drops until $\mathrm{C}_{7}$, after which the affinity increases. Interestingly, the tighter inhibition constants for these larger alcohols are accompanied by a distinct change in inhibition from competitive to mixed, suggesting that the alcohol is able to bind to both free enzyme (E) and the enzyme-substrate (ES) complex. Incubation of the enzyme complex with these longer-chain alcohols with and without NADH for $1 \mathrm{~h}$ did not yield any significant loss in activity compared with the control after dialysis, indicating that the change in inhibition type is not a result of enzyme inactivation. Given that product-bound structures of $\mathrm{MMOH}$ have demonstrated alternative small molecule binding cavities (Sazinsky \& Lippard, 2005), it is possible that the uncompetitive nature of primary alcohols larger than $\mathrm{C}_{6}$ is derived from the preferential binding to alternative hydrophobic pockets rather than to the active site.

Inhibition constants for $\mathrm{C}_{1}-\mathrm{C}_{9}$ secondary alcohols were also measured (Fig. 2, white bars). Three distinct observations were made in comparison with primary alcohols. First, all secondary alcohols bound with less affinity than their primary counterparts, indicating that the active site of sBMO is optimized for linear molecules. Second, the break in decreasing $K_{\mathrm{ic}}$ values was found between $\mathrm{C}_{4}$ and $\mathrm{C}_{5}$, rather than $\mathrm{C}_{5}$ and $\mathrm{C}_{6}$ as for primary alcohols. Third, the break from competitive to mixed inhibition occurred at $\mathrm{C}_{8}$ rather than $\mathrm{C}_{7}$, indicating that secondary alcohols do not bind to the proposed alternative binding pockets as well as primary alcohols. Lastly, branched alcohols, such as 2methyl-2-butanol $\left(K_{\mathrm{ic}}=1.45 \pm 0.08 \mathrm{mM}\right)$, bound poorly, providing further evidence that the active site of sBMO is structurally optimized for linear molecules.

\section{Effect of BMOB}

Component B of the sMMO system (MMOB) has profound effects on both the rate of $\mathrm{MMOH}$ catalysis and product distribution (Wallar \& Lipscomb, 1996). Our previous characterization of purified sBMO revealed that BMOB had little effect on either rate enhancement or product distribution (Dubbels et al., 2007); however, improvements in culturing $T$. butanivorans have yielded $\mathrm{BMOH}$ with catalytic properties more dependent on BMOB (Fig. 3a). At a ratio of $3: 1 \mathrm{BMOB}: \mathrm{BMOH}$, the turnover rate of nitrobenzene increased 14-fold. Similar effects were seen for ethylene and butane oxidation. Although not as dramatic as the sMMO system, the stimulation of activity by BMOB is more consistent with the role of regulatory components in other di-iron monooxygenases. Unlike MMOB, addition of $\mathrm{BMOB}$ had little effect on the product distribution of butane oxidation, generating approximately $80: 20$ and 85:15 1butanol:2-butanol without and with $\mathrm{BMOB}$, respectively.

Because substrate turnover by sMMO without MMOB is slow, elucidating its effects on $\mathrm{MMOH}$ is difficult and continues to be an active area of research (Mitic et al., 2008). However, because the BMOH-BMOR complex oxidizes substrates at rates of $\sim 40 \mathrm{nmol} \mathrm{min} \mathrm{mg}^{-1}$ without $\mathrm{BMOB}$, we were able to measure the influence of the latter on the inhibition of alcohols during steady-state turnover. Only $\mathrm{C}_{3}-\mathrm{C}_{6}$ alcohols were examined, because this was the chain-length range in which breaks in binding affinities were observed. All alcohols bound with less affinity to $\mathrm{BMOH}$ when $\mathrm{BMOB}$ was not present (Table 2, Fig. 3b). As a consequence, the break in primary alcohol binding affinity was observed between $\mathrm{C}_{4}$ and $\mathrm{C}_{5}$ rather than $\mathrm{C}_{5}$ and $\mathrm{C}_{6} \cdot \mathrm{C}_{3}-\mathrm{C}_{6}$ secondary alcohols displayed a much less pronounced break between $\mathrm{C}_{4}$ and $\mathrm{C}_{5}$. 2-Methyl2-butanol could not effectively inhibit sBMO without BMOB present. Lastly, 1-hexanol displayed weak uncompetitive binding characteristics $\left(K_{\mathrm{iu}}>400 \mu \mathrm{M}\right)$ without BMOB, implying a possible shift away from active-site binding. The data suggest that BMOB helps to open the active site of $\mathrm{BMOH}$ for more efficient substrate access. Similarly, the dissociation of BMOB after substrate turnover may facilitate the release of products. Similar conclusions have been reached in detailed mutational and kinetic analyses in the sMMO system, in which MMOB plays a role in regulating substrate access and product release (Wallar \& Lipscomb, 2001; Zheng \& Lipscomb, 2006). Whether BMOB enhances the activation of oxygen as $\mathrm{MMOB}$ does for $\mathrm{MMOH}$ remains to be determined.

\section{Special case of methane oxidation}

Methanol is not an efficient inhibitor of $\mathrm{BMOH}$, even though methanol accumulation during methane oxidation ceases once low micromolar concentrations have been 

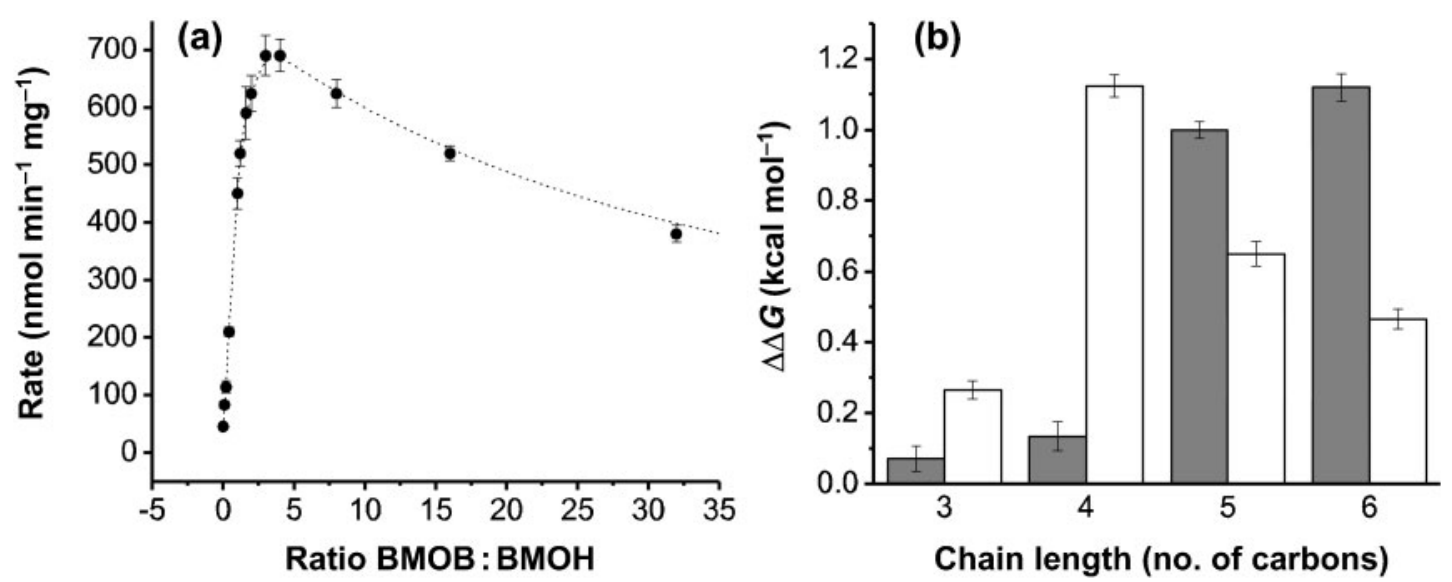

Fig. 3. Influence of $\mathrm{BMOB}$ on the $\mathrm{sBMO}$ complex. (a) Titration of $\mathrm{BMOB}$ into a fixed concentration of $\mathrm{BMOH}$ during steadystate nitrobenzene oxidation. (b) The energetic difference (in $\mathrm{kcal} \mathrm{mol}^{-1}$ ) between alcohol binding to the $\mathrm{BMOH}-\mathrm{BMOB}$ complex and to $\mathrm{BMOH}$ alone for primary alcohols (shaded bars) and for secondary alcohols with the hydroxyl group at the second carbon position (white bars). Positive values indicate weaker binding without BMOB. Error bars represent SD from three replicates.

reached both in vivo (Halsey et al., 2006) and in vitro. Even though all the physiologically relevant alcohols were more effective inhibitors than methanol, no stoppage in product accumulation was observed during oxidation of alkanes $\geqslant \mathrm{C}_{2}$, presumably due to effective competition between substrate and product. Moreover, in vitro characterization of the 1butanol dehydrogenases $\mathrm{BDH}$ and $\mathrm{BOH}$ from T. butanivorans showed that the $K_{\mathrm{m}}$ for 1-butanol was well below the $K_{\mathrm{ic}}$ for sBMO, which further emphasizes that sBMO inhibition by alcohols is unlikely to play an important physiological role in the metabolism of longer-chain alkanes (Vangnai \& Arp, 2001; Vangnai et al., 2002). As such, methane oxidation clearly represents a unique case among alkanes.

Table 2. Alcohol inhibition constants for WT BMOH

Error values represent SD from three replicates.

\begin{tabular}{|c|c|c|c|c|c|}
\hline \multirow[t]{2}{*}{ Inhibitor } & \multirow[t]{2}{*}{ Alcohol position } & \multicolumn{2}{|c|}{ With BMOB } & \multicolumn{2}{|c|}{ Without BMOB } \\
\hline & & $K_{\mathrm{ic}}(\mu \mathrm{M})$ & $K_{\mathrm{iu}}(\mu \mathrm{M})$ & $K_{\mathrm{ic}}(\mu \mathrm{M})$ & $K_{\mathrm{iu}}(\mu \mathrm{M})$ \\
\hline Methanol & 1 & $1250 \pm 60$ & $\mathrm{NA}^{*}$ & - & - \\
\hline Ethanol & 1 & $150 \pm 21$ & $\mathrm{NA}$ & - & - \\
\hline \multirow[t]{2}{*}{ Propanol } & 1 & $69 \pm 11$ & NA & $78 \pm 5$ & NA \\
\hline & 2 & $349 \pm 25$ & $\mathrm{NA}$ & $550 \pm 35$ & NA \\
\hline \multirow[t]{2}{*}{ Butanol } & 1 & $23 \pm 3$ & $\mathrm{NA}$ & $29 \pm 5$ & NA \\
\hline & 2 & $69 \pm 9$ & $\mathrm{NA}$ & $475 \pm 27$ & $\mathrm{NA}$ \\
\hline \multirow[t]{2}{*}{ Pentanol } & 1 & $8.8 \pm 1.0$ & $\mathrm{NA}$ & $49 \pm 3$ & $\mathrm{NA}$ \\
\hline & 2 & $180 \pm 20$ & $\mathrm{NA}$ & $549 \pm 47$ & $\mathrm{NA}$ \\
\hline \multirow[t]{2}{*}{ Hexanol } & 1 & $13 \pm 1.4$ & $\mathrm{NA}$ & $89 \pm 14$ & $414 \pm 61$ \\
\hline & 2 & $580 \pm 50$ & NA & $1290 \pm 75$ & $\mathrm{NA}$ \\
\hline \multirow[t]{2}{*}{ Heptanol } & 1 & $127 \pm 14$ & $102 \pm 7$ & - & - \\
\hline & 2 & $1830 \pm 90$ & $\mathrm{NA}$ & - & - \\
\hline \multirow[t]{2}{*}{ Octanol } & 1 & $86 \pm 16$ & $139 \pm 24$ & - & - \\
\hline & 2 & $521 \pm 65$ & $1200 \pm 175$ & - & - \\
\hline \multirow[t]{2}{*}{ Nonanol } & 1 & $28 \pm 8$ & $29 \pm 4$ & - & - \\
\hline & 2 & $142 \pm 16$ & $233 \pm 21$ & - & - \\
\hline 2-Methyl-1-butanol & 1 & $515 \pm 37$ & $\mathrm{NA}$ & - & - \\
\hline 2-Methyl-2-butanol & 2 & $1450 \pm 80$ & $\mathrm{NA}$ & $\mathrm{NA}$ & $\mathrm{NA}$ \\
\hline
\end{tabular}

${ }^{*}$ NA, Not observed. Inhibition constants greater than $10 \mathrm{mM}$ were not considered. 
One explanation of the apparent steady level of methanol during methane oxidation is that it is the result of an equilibrium between methane conversion to methanol and methanol conversion to formaldehyde, in which case methane and methanol consumption would be kinetically indistinguishable. Methanol has also been reported to be a substrate for sMMO, but the low micromolar $K_{\mathrm{m}}$ for methane and approximately $1 \mathrm{mM} K_{\mathrm{m}}$ for methanol make methanol turnover by sMMO physiologically irrelevant (Colby et al., 1977). Kinetic analysis of methane and methanol as substrates of sBMO showed they have nearly identical $K_{\mathrm{m}}$ and $k_{\text {cat }}$ values (Table 3 ). As a result, reactions that initially contain only methane generate formaldehyde once methanol begins to accumulate. As the methanol concentration increases, the rate of formaldehyde formation increases until it equals the rate of methanol formation and a steady-state level of methanol is reached (Fig. 4). This non-discrimination of $\mathrm{C}_{1}$ substrates by $\mathrm{BMOH}$ is partially alleviated by an alteration in residue 113 from Gly to the corresponding $\mathrm{MMOH}$ amino acid, Asn. Kinetic characterization of the $\mathrm{G} 113 \mathrm{~N}$ variant of $\mathrm{BMOH}$ (Table 3) showed that this alteration makes sBMO more specific for methane than methanol, primarily by lowering the $K_{\mathrm{m}}$ for methane 3.3-fold. This conserved $\mathrm{MMOH}$ Asn residue appears to be critical in maintaining sMMO specificity for methane over methanol, thereby eliminating effective substrate competition between the two.

\section{DISCUSSION}

The first step in metabolizing an alkane requires the input of energy to cleave the highly stable $\mathrm{C}-\mathrm{H}$ bond to form an alcohol, which can then be metabolized further in order to provide both the energy and carbon needs for the cell. Attempts to purify alkane monooxygenases from a variety of organisms have proven difficult (Shennan, 2006), limiting in-depth kinetic and structural characterization. In this study, we have characterized an SBMO complex, which is the closest relative to the well-studied sMMO enzymes that has been purified to homogeneity with high activity.

\section{Substrate specificity}

With the exception of sMMO, substrate specificity characterizations of alkane monooxygenases are mostly limited to in vivo analyses and only compare relative rates of substrate turnover using saturating concentrations of substrate, thereby neglecting differences in $K_{\mathrm{m}}$ values. Our analysis of sBMO shows that even though methane has the highest turnover rate of the alkanes tested, it is clearly a poor substrate due to the high $K_{\mathrm{m}}$ relative to $\mathrm{C}_{2}-\mathrm{C}_{5}$ alkanes. As such, sBMO is very effective at discriminating between methane and longer alkane substrates. While sMMO is more specific for methane over $\mathrm{C}_{2}-\mathrm{C}_{5}$ alkanes, the apparent discrimination for its physiological substrate over longer alkanes is much less striking than that of sBMO. In sMMO, the methane $\mathrm{V}_{\text {max }}: K_{\mathrm{m}}$ ratio reported for Methylococcus capsulatus sMMO is only 13-fold higher than that of ethane, and only sevenfold higher than that of propane (Green \& Dalton, 1986). For sBMO, the equivalent values for ethane and propane are 290- and 580 -fold higher than that for methane, respectively. While it is difficult to compare substrate specificities with those of other alkane monooxygenases due to limited in vitro characterization, in vivo studies with soluble di-ironcontaining propane monooxygenases from Gordonia sp. TY-5, Mycobacterium sp. TY-6 and Pseudonocardia sp. TY7 have suggested that they are similar to sBMO in that they are specific for short-chain $\mathrm{C}_{2}-\mathrm{C}_{6}$ alkanes but poorly suited for methane oxidation (Kotani et al., 2003, 2006).

While particulate methane monooxygenase (pMMO) is unusual in that it has a narrow alkane substrate range that includes only linear $\mathrm{C}_{1}-\mathrm{C}_{5}$ alkanes (Elliott et al., 1997), wide substrate ranges are not uncommon in membranebound alkane monooxygenases. The alkB hydroxylase from Pseudomonas putida GPo1 is capable of oxidizing large $\left(>\mathrm{C}_{12}\right)$ linear alkanes and substituted cyclic alkanes at similar rates (van Beilen et al., 1994), while also oxidizing the smaller growth substrates propane and butane with high affinity ( $K_{\mathrm{s}} 66$ and $13 \mu \mathrm{M}$, respectively) (Johnson \& Hyman, 2006). The alkane hydroxylase from propaneutilizing Mycobacterium vaccae JOB5 has also recently been characterized as an alkB hydroxylase (Lopes Ferreira et al., 2007), and has a low reported $K_{\mathrm{s}}$ for propane of 3.3$4.4 \mu \mathrm{M}$ but high $K_{\mathrm{s}}$ values for branched substrates tertbutyl alcohol and methyl tert-butyl ether (1.36 and $1.18 \mathrm{mM}$, respectively) (Smith et al., 2003). The soluble haem-containing CYP153A6 alkane hydroxylase from Mycobacterium sp. HXN-1500 has been reported to have low $K_{\mathrm{d}}$ values $(20 \mathrm{nM})$ for $\mathrm{C}_{9}-\mathrm{C}_{11}$ growth substrates; however, $K_{\mathrm{d}}$ values for cyclic hydrocarbons are nearly 200fold higher (Funhoff et al., 2006). Despite the large

Table 3. Kinetic parameters for WT and G113N BMOH oxidation of methane and methanol

Error values represent SD from three replicates.

\begin{tabular}{|c|c|c|c|c|c|c|}
\hline \multirow[t]{2}{*}{ Substrate } & \multicolumn{2}{|c|}{$K_{\mathrm{m}}(\mu \mathrm{M})$} & \multicolumn{2}{|c|}{$k_{\text {cat }}\left(\mathrm{s}^{-1}\right)$} & \multicolumn{2}{|c|}{$k_{\mathrm{cat}} / K_{\mathrm{m}}\left(10^{-4} \mu \mathrm{M}^{-1} \mathrm{~s}^{-1}\right)$} \\
\hline & WT & G113N & WT & G113N & WT & G113N \\
\hline Methane & $1100 \pm 140$ & $340 \pm 20$ & $1.3 \pm 0.1$ & $0.13 \pm 0.01$ & 11.8 & 3.8 \\
\hline Methanol & $1250 \pm 60$ & $750 \pm 40$ & $1.6 \pm 0.1$ & $0.21 \pm 0.02$ & 12.8 & 2.8 \\
\hline
\end{tabular}




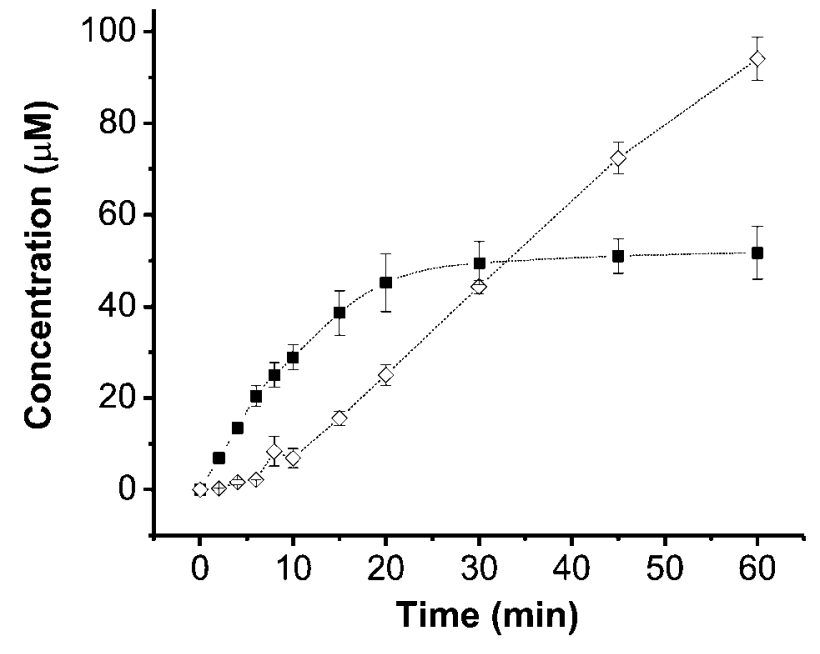

Fig. 4. Oxidation of methane by sBMO. Concentrations of both methanol $(\boldsymbol{\square})$ and formaldehyde $(\diamond)$ were measured in a reaction initially containing only methane as a substrate. Error bars represent SD from three replicates.

substrate ranges for these alkane monooxygenases, these data, together with our kinetic analyses of sBMO, emphasize the importance for these alkane monooxygenases to maintain high specificities for physiological substrates in order to out-compete oxidation of molecules that would not provide the carbon and energy needs to sustain cell growth.

Studies have characterized the different iron-oxygen intermediates generated by the hydrocarbon oxidizers toluene/ $o$ xylene monooxygenase (ToMO) and sMMO. While sMMO generates a diamond core bis- $\mu$-oxo- $\left(\mathrm{Fe}^{\mathrm{IV}}\right)_{2}$ intermediate (Shu et al., 1997), ToMO generates a weaker oxidizing peroxo-bridged-( $\left.\mathrm{Fe}^{\mathrm{III}}\right)_{2}$ intermediate (Murray et al., 2007), suggesting that this may be a means of substrate selection. This type of selection mechanism, whereby sBMO generates a weaker oxidizing intermediate in order to take advantage of the weaker $\mathrm{C}-\mathrm{H}$ bonds of longer-chain alkanes compared with methane, is unlikely, given that it oxidizes methane at faster rates than longer-chain alkanes and that it hydroxylates the primary carbon. Therefore, the basis for substrate discrimination is more likely to be based on structural differences in the binding pockets than to be based on different chemical mechanisms. Unfortunately, these structural mechanisms are still poorly understood and are complicated by the observation that naphthalene and methane are both substrates of sMMO and sBMO, despite their fully buried, identical active sites (Halsey et al., 2006; Rosenzweig et al., 1997). However, we have identified one particular residue in the $\alpha$-subunit of BMOH, Gly-113, which contributes toward defining these specificities. As such, further coordinated mutational analyses of these homologues will certainly provide additional insight into the mechanism of substrate selection.

\section{Component B}

Several roles for the small regulatory component have been observed for soluble di-iron-containing multicomponent monooxygenases. Recent studies have demonstrated that in order to enhance the activity of $\mathrm{MMOH}, \mathrm{MMOB}$ must both (i) induce a geometric rearrangement of a single $\mathrm{Fe}$ atom (Fe2) to enhance its reactivity with oxygen, and (ii) cause a more global conformational change within the active site to allow for efficient $\mathrm{O}_{2}$ access (Mitic et al., 2008; Schwartz et al., 2008). The data shown here demonstrate that BMOB also has a large effect on substrate turnover rates (14-fold increase in activity), although this effect is modest compared with that of sMMO. While our data continue to emphasize the importance of these regulatory components in di-iron monooxygenases for maintaining proper substrate selection and efficient product release, one significant difference remains between the sBMO system and both sMMO and other toluene oxidizers: the regulatory component in sBMO does not significantly alter the product regioselectivity for either alkanes or nitrobenzene. The change in regioselectivity caused by MMOB in SMMO was considered to be a consequence of the requirement that a global conformation change within the active site must occur for proper $\mathrm{O}_{2}$ access (Mitic et al., 2008). While it appears that a conformational change within the active site of $\mathrm{BMOH}$ must be induced by $\mathrm{BMOB}$, the mechanism must be different from that of sMMO, where product distribution does change substantially. As such, sBMO provides a unique system in which to uncover details about the nature of the active site conformation changes necessary to enhance $\mathrm{O}_{2}$ binding and activation without altering the position of substrate hydroxylation.

The kinetic studies of purified sBMO demonstrate that it is highly specific for linear alkanes $\geqslant \mathrm{C}_{2}$, while effectively filtering out methane oxidation, even though sBMO and sMMO share identical residues in the active site. While several physiological and enzymic implications can be made, it is clear that sBMO can be a useful tool in helping to elucidate specific factors that influence substrate specificity and activity in bacterial alkane monooxygenases. Efforts to crystallize $\mathrm{BMOH}$ are currently under way in our laboratory to address such comparisons from a structural point of view.

\section{ACKNOWLEDGEMENTS}

We thank Michael Schimerlik for his helpful comments and suggestions during the course of this study, and Christine Lastovica and Lisa Roberton for culturing and harvesting of cells. We are grateful for the research support from the National Institutes of Health, grant number 5RO1 GM56128-06.

\section{REFERENCES}

Arp, D. J. (1999). Butane metabolism by butane-grown 'Pseudomonas butanovora'. Microbiology 145, 1173-1180. 
Ausubel, F. M., Brent, R., Kingston, R. E., Moore, D. D., Seidman, J. G., Smith, J. A. \& Struhl, K. (2003). Current Protocols in Molecular Biology. New York: Green Publishing \& Wiley Interscience.

Borodina, E., Nichol, T., Dumont, M. G., Smith, T. J. \& Murrell, J. C. (2007). Mutagenesis of the "leucine gate" to explore the basis of catalytic versatility in soluble methane monooxygenase. Appl Environ Microbiol 73, 6460-6467.

Burton, S. G. (2003). Oxidizing enzymes as biocatalysts. Trends Biotechnol 21, 543-549.

Colby, J., Stirling, D. I. \& Dalton, H. (1977). The soluble methane mono-oxygenase of Methylococcus capsulatus (Bath). Its ability to oxygenate $n$-alkanes, $n$-alkenes, ethers, and alicyclic, aromatic and heterocyclic compounds. Biochem J 165, 395-402.

Cornish-Bowden, A. (1995). Fundamentals of Enzyme Kinetics, p. 108. London: Portland Press Ltd.

Doughty, D. M., Halsey, K. H., Vieville, C. J., Sayavedra-Soto, L. A., Arp, D. J. \& Bottomley, P. J. (2007). Propionate inactivation of butane monooxygenase activity in 'Pseudomonas butanovora': biochemical and physiological implications. Microbiology 153, 3722-3729.

Dubbels, B. L., Sayavedra-Soto, L. A. \& Arp, D. J. (2007). Butane monooxygenase of 'Pseudomonas butanovora': purification and biochemical characterization of a terminal-alkane hydroxylating diiron monooxygenase. Microbiology 153, 1808-1816.

Dubbels, B. L., Sayavedra-Soto, L. A., Bottomley, P. J. \& Arp, D. J. (2009). Thauera butanivorans sp. nov., a C2-C9 alkane oxidizing bacterium previously referred to as 'Pseudomonas butanovora'. Int J Syst Evol Microbiol (in press).

Elliott, S. J., Zhu, M., Tso, L., Nguyen, H. H. T., Yip, J. H. K. \& Chan, S. I. (1997). Regio- and stereoselectivity of particulate methane monooxygenase from Methylococcus capsulatus (Bath). J Am Chem Soc 119, 9949-9955.

Enzien, M. V., Picardal, F., Hazen, T. C., Arnold, R. G. \& Fliermans, C. B. (1994). Reductive dechlorination of trichloroethylene and tetrachloroethylene under aerobic conditions in a sediment column. Appl Environ Microbiol 60, 2200-2204.

Froland, W. A., Andersson, K. K., Lee, S. K., Liu, Y. \& Lipscomb, J. D. (1992). Methane monooxygenase component B and reductase alter the regioselectivity of the hydroxylase component-catalyzed reactions. A novel role for protein-protein interactions in an oxygenase mechanism. J Biol Chem 267, 17588-17597.

Funhoff, E. G., Bauer, U., Garcia-Rubio, I., Witholt, B. \& van Beilen, J. B. (2006). CYP153A6, a soluble P450 oxygenase catalyzing terminalalkane hydroxylation. J Bacteriol 188, 5220-5227.

Green, J. \& Dalton, H. (1986). Steady-state kinetic analysis of soluble methane mono-oxygenase from Methylococcus capsulatus (Bath). Biochem J 236, 155-162.

Halsey, K. H., Sayavedra-Soto, L. A., Bottomley, P. J. \& Arp, D. J. (2006). Site-directed amino acid substitutions in the hydroxylase $\alpha$ subunit of butane monooxygenase from Pseudomonas butanovora: implications for substrates knocking at the gate. J Bacteriol 188, 49624969.

Halsey, K. H., Doughty, D. M., Sayavedra-Soto, L. A., Bottomley, P. J. \& Arp, D. J. (2007). Evidence for modified mechanisms of chloroethene oxidation in Pseudomonas butanovora mutants containing single amino acid substitutions in the hydroxylase $\alpha$-subunit of butane monooxygenase. J Bacteriol 189, 5068-5074.

Johnson, E. L. \& Hyman, M. R. (2006). Propane and $n$-butane oxidation by Pseudomonas putida GPol. Appl Environ Microbiol 72, 950-952.

Korth, H.-G. \& Sicking, W. (1997). Prediction of methyl C-H bond dissociation energies by density functional theory calculations. J Chem Soc, Perkin Trans 2 715-719.
Kotani, T., Yamamoto, T., Yurimoto, H., Sakai, Y. \& Kato, N. (2003). Propane monooxygenase and $\mathrm{NAD}^{+}$-dependent secondary alcohol dehydrogenase in propane metabolism by Gordonia sp. strain TY-5. J Bacteriol 185, 7120-7128.

Kotani, T., Kawashima, Y., Yurimoto, H., Kato, N. \& Sakai, Y. (2006). Gene structure and regulation of alkane monooxygenases in propaneutilizing Mycobacterium sp. TY-6 and Pseudonocardia sp. TY-7. J Biosci Bioeng 102, 184-192.

Leahy, J. G., Batchelor, P. J. \& Morcomb, S. M. (2003). Evolution of the soluble diiron monooxygenases. FEMS Microbiol Rev 27, 449-479.

Lee, S. K., Nesheim, J. C. \& Lipscomb, J. D. (1993). Transient intermediates of the methane monooxygenase catalytic cycle. J Biol Chem 268, 21569-21577.

Leskovac, V. (2003). Comprehensive Enzyme Kinetics. New York: Kluwer Academic/Plenum Publishers.

Li, Q., Sritharathikhun, P. \& Motomizu, S. (2007). Development of novel reagent for Hantzsch reaction for the determination of formaldehyde by spectrophotometry and fluorometry. Anal Sci 23, 413-417.

Lide, D. R. \& Frederikse, H. P. R. (1995). CRC Handbook of Chemistry and Physics. Boca Raton, FL: CRC Press.

Lopes Ferreira, N., Mathis, H., Labbe, D., Monot, F., Greer, C. W. \& Fayolle-Guichard, F. (2007). n-Alkane assimilation and tert-butyl alcohol (TBA) oxidation capacity in Mycobacterium austroafricanum strains. Appl Microbiol Biotechnol 75, 909-919.

Mitic, N., Schwartz, J. K., Brazeau, B. J., Lipscomb, J. D. \& Solomon, E. I. (2008). CD and MCD studies of the effects of component B variant binding on the biferrous active site of methane monooxygenase. Biochemistry 47, 8386-8397.

Murray, L. J., Naik, S. G., Ortillo, D. O., Garcia-Serres, R., Lee, J. K., Huynh, B. H. \& Lippard, S. J. (2007). Characterization of the areneoxidizing intermediate in ToMOH as a diiron(III) species. J Am Chem Soc 129, 14500-14510.

Nesheim, J. C. \& Lipscomb, J. D. (1996). Large kinetic isotope effects in methane oxidation catalyzed by methane monooxygenase: evidence for $\mathrm{C}-\mathrm{H}$ bond cleavage in a reaction cycle intermediate. Biochemistry 35, 10240-10247.

Pace, C. N., Shirley, B. A., McNutt, M. \& Gajiwala, K. (1996). Forces contributing to the conformational stability of proteins. FASEB J 10, 75-83.

Parales, R. E., Bruce, N. C., Schmid, A. \& Wackett, L. P. (2002). Biodegradation, biotransformation, and biocatalysis (B3). Appl Environ Microbiol 68, 4699-4709.

Percival, M. D. (1991). Human 5-lipoxygenase contains an essential iron. J Biol Chem 266, 10058-10061.

Rosenzweig, A. C., Brandstetter, H., Whittington, D. A., Nordlund, P., Lippard, S. J. \& Frederick, C. A. (1997). Crystal structures of the methane monooxygenase hydroxylase from Methylococcus capsulatus (Bath): implications for substrate gating and component interactions. Proteins 29, 141-152.

Sambrook, J., Fritsch, E. F. \& Maniatis, T. (1989). Molecular Cloning: a Laboratory Manual. Cold Spring Harbor, NY: Cold Spring Harbor Laboratory.

Sayavedra-Soto, L. A., Doughty, D. M., Kurth, E. G., Bottomley, P. J. \& Arp, D. J. (2005). Product and product-independent induction of butane oxidation in Pseudomonas butanovora. FEMS Microbiol Lett 250, 111-116.

Sazinsky, M. H. \& Lippard, S. J. (2005). Product bound structures of the soluble methane monooxygenase hydroxylase from Methylococcus capsulatus (Bath): protein motion in the $\alpha$-subunit. J Am Chem Soc 127, 5814-5825. 
Schwartz, J. K., Wei, P. P., Mitchell, K. H., Fox, B. G. \& Solomon, E. I. (2008). Geometric and electronic structure studies of the binuclear nonheme ferrous active site of toluene-4-monooxygenase: parallels with methane monooxygenase and insight into the role of the effector proteins in $\mathrm{O}_{2}$ activation. $J$ Am Chem Soc 130, 7098-7109.

Shennan, J. L. (2006). Utilisation of C2-C4 gaseous hydrocarbons and isoprene by microorganisms. J Chem Technol Biotechnol 81, 237256.

Shu, L., Nesheim, J. C., Kauffmann, K., Munck, E., Lipscomb, J. D. \& Que, L., Jr (1997). An $\mathrm{Fe}_{2}{ }^{\mathrm{IV}} \mathrm{O}_{2}$ diamond core structure for the key intermediate Q of methane monooxygenase. Science 275, 515-518.

Sluis, M. K., Sayavedra-Soto, L. A. \& Arp, D. J. (2002). Molecular analysis of the soluble butane monooxygenase from 'Pseudomonas butanovora'. Microbiology 148, 3617-3629.

Smith, T. J. \& Dalton, H. (2004). Biocatalysis by methane monooxygenase and its implications for the petroleum industry. In Petroleum Biotechnology, Developments and Perspectives, pp. 177-192. Edited by R. Vazquez-Duhalt \& R. Qintero-Ramirez. Amsterdam: Elsevier.

Smith, C. A., O'Reilly, K. T. \& Hyman, M. R. (2003). Characterization of the initial reactions during the cometabolic oxidation of methyl tert-butyl ether by propane-grown Mycobacterium vaccae JOB5. Appl Environ Microbiol 69, 796-804.

Tabor, S. \& Richardson, C. C. (1985). A bacteriophage T7 RNA polymerase/promoter system for controlled exclusive expression of specific genes. Proc Natl Acad Sci U S A 82, 1074-1078.

Takahashi, J., Ichikawa, Y., Sagae, H., Komura, I., Kanou, H. \& Yamada, K. (1980). Isolation and identification of $n$-butane assimilating bacterium. Agric Biol Chem 44, 1835-1840. van Beilen, J. B. \& Funhoff, E. G. (2007). Alkane hydroxylases involved in microbial alkane degradation. Appl Microbiol Biotechnol 74, 13-21.

van Beilen, J. B., Kingma, J. \& Witholt, B. (1994). Substrate specificity of the alkane hydroxylase system of Pseudomonas oleovorans GPol. Enzyme Microb Technol 16, 904-911.

Vangnai, A. S. \& Arp, D. J. (2001). An inducible 1-butanol dehydrogenase, a quinohaemoprotein, is involved in the oxidation of butane by 'Pseudomonas butanovora'. Microbiology 147, 745-756.

Vangnai, A. S., Sayavedra-Soto, L. A. \& Arp, D. J. (2002). Roles for the two 1-butanol dehydrogenases of Pseudomonas butanovora in butane and 1-butanol metabolism. J Bacteriol 184, 4343-4350.

Wallar, B. J. \& Lipscomb, J. D. (1996). Dioxygen activation by enzymes containing binuclear non-heme iron clusters. Chem Rev 96, 2625-2658.

Wallar, B. J. \& Lipscomb, J. D. (2001). Methane monooxygenase component B mutants alter the kinetics of steps throughout the catalytic cycle. Biochemistry 40, 2220-2233.

Werner, D. S., Lee, T. R. \& Lawrence, D. S. (1996). Is protein kinase substrate efficacy a reliable barometer for successful inhibitor design? J Biol Chem 271, 180-185.

Zheng, H. \& Lipscomb, J. D. (2006). Regulation of methane monooxygenase catalysis based on size exclusion and quantum tunneling. Biochemistry 45, 1685-1692.

Zhu, C. Z., Ouyang, B., Wang, J. Q., Huang, L., Dong, W. B. \& Hou, H. Q. (2007). Photochemistry in the mixed aqueous solution of nitrobenzene and nitrous acid as initiated by the $355 \mathrm{~nm}$ UV light. Chemosphere 67, 855-861.

Edited by: J. A. Vorholt 